\title{
La «Costum de la ciutat i Regne de València» de 1238
}

\author{
Vicent Garcia Edo (garciav@uji.es) \\ Universitat Jaume I de Castelló
}

Poques setmanes després de la capitulació dels musulmans de la ciutat de València, el rei Jaume I va promulgar la «Costum de la ciutat i regne de València», ${ }^{1}$ un text legislatiu extens que es pot datar a finals d'octubre o principis de novembre de 1238 (Garcia Edo, 1996), després d'un llarg treball preparatori realitzat pels juristes de la Cancelleria reial, coincidint amb els mesos de setge de la ciutat. Actualment conservem el text complet de la «Costum», ${ }^{2}$ però no la versió original sinó la resultant de les addicions i millores efectuades durant la resta del regnat d'aquest monarca, fins a la seua mort en juliol de 1276.

Des de finals del segle XIX molts historiadors han fet estudis al voltant de la «Costum» (o dels furs que la componen), treballs de conjunt en uns casos i temàtics en altres, i també s'han realitzat diverses edicions completes del text, tant de la versió llatina de 1238 com de

\footnotetext{
${ }^{1}$ Aquesta va ser la primera denominació oficial de l'obra (segons figura al pròleg i a l'articulat del text), tot i que ningú sol utilitzar-la, ja que es prefereix la forma abreujada «Costum de València»-que pot donar lloc a confusió - i tampoc seria la definitiva, ja que més endavant es va generalitzar el nom de «Furs de València». Però açò darrer no va ocórrer coincidint amb la primera gran intervenció del rei Jaume I, a través de la Cancelleria reial, sobre el text original per tal de millorar-lo, traduir-lo del llatí al romanç i confirmar-lo per primera vegada (1261), ni tampoc a la segona, on es va tornar a millorar, ampliar i confirmar (1271), ja que quan llegim els privilegis que se'n deriven d'eixes dos actuacions, en realitat Jaume I indica que en un i altre cas està jurant els «foros et consuetudines Valencie». La diferència entre el text fundacional del regne de Valencia, de 1238, i les cites posteriors de 1261 i 1271 és clara: en el primer es parla únicament de «costums» de la ciutat i regne de València, però a la documentació notarial conservada a partir de 1239, cada volta que es fa referència a un article de la «Costum» es diu que és un «fur», paraula que va adquirint protagonisme els anys immediatament posteriors, fins al punt que en els documents de 1261 i 1271 es parla en els dos casos de «furs» $\mathrm{i}$ «costums», en eixe ordre, com a primer pas per a la posterior i definitiva denominació del text legislatiu jaumí amb la fórmula de «Furs de València», cosa que sense voler afinar més ara ja es troba consolidada oficialment l'any 1329 quan, a l'hora de redactar un nou manuscrit oficial del text, els juristes diferencien entre els «furs vells» del regne, entenent que són els del rei Jaume I, i els «furs nous» aprovats per les Corts de 1329-1330. Enmig d'aquests dos textos no n'hi ha d'altres, tot i que des del segle xv se solen considerar furs els continguts pels privilegis «Magnum» del rei Pere el Gran (1283) i «Capitulat» del rei Jaume II (1302) i es van incorporar com a tals a les edicions impreses dels Furs, tant a la cronològica de 1482 com a la sistemàtica de 1547-1548.

${ }^{2}$ Dels diversos manuscrits dels segles XIV i Xv arribats als nostres dies, el més antic de tots és el conservat a l'Arxiu Municipal de València. Es va confeccionar coincidint amb les Corts de 1329-1330, per la necessitat de disposar d'un exemplar nou, ja que l'anterior que obrava en poder del Consell municipal de la ciutat, potser de finals del regnat de Jaume I, es trobava en mal estat degut a l'ús constant que d'ell se n'havia fet. El nou manuscrit va ser obra d'un copista anònim que va fer un treball molt acurat, i després el va revisar el notari Bonanat Sapera, que exercia a la Cancelleria reial i va aplicar per a la revisió la mateixa metodologia que si es tractara d'un document notarial ordinari, de manera que a l'hora d'autoritzar-lo dedicà vàries pàgines a indicar totes les esmenes, raspadures, interlineats i altres alteracions que va poder observar acarant amb l'original, amb la qual cosa aquest nou manuscrit tenia, des d'un punt de vista legal, el mateix valor legal que el del manuscrit del qual es va copiar. Aquest text és el que va servir de base principal per a realitzar l'actual edició crítica existent dels Furs promulgats per Jaume I (Colón i Garcia Edo, 1970-1999).
} 
la versió romanç, traducció de l'anterior realitzada entre 1260 i 1261, malgrat la qual cosa encara queda molt de treball per fer, ja que el text és molt extens i complex i, al llarg dels més de 1.500 articles (o furs) de què consta, hi ha moltes coses per estudiar $\mathrm{i}$, a més, també hi ha diverses qüestions per aclarir, en haver estat algunes d'elles motiu de controvèrsia entre els historiadors, com puga ser, per exemple, la derivada del dubte de si la «Costum» de 1238 tenia caràcter local o territorial, o les dues coses alhora. ${ }^{3}$ Alguns pensen que en 1238 constituïa només una manifestació de dret municipal i, per tant, era prou més breu, i que després es va redactar una segona obra molt més extensa, promulgada en 1261, que va incloure el dret vell i va ser d'aplicació a tot el regne de València, el resultat de la qual seria el text que coneixem en l'actualitat, sense els afegits que conté i que es poden identificar amb certa facilitat. Altres, en canvi, consideren que aquesta «Costum» va ser d'aplicació des del primer dia no tan sols a la ciutat sinó al conjunt del regne de València i amb l'extensió amb què la coneixem (sense els canvis i els afegits), tot i que tardaria a estendre's pel territori valencià i només a les poblacions que habitaven cristians ja que, d'una banda, en 1238 encara hi havia una gran part del regne per conquerir i, d'altra, en l'àrea conquerida abans que la ciutat de València ja s'havien aplicat altres furs forans com a referent, mitjançant les cartes de poblament, per tal de pallliar la inexistència d'un dret general valencià propi.

La primera opinió es justificaria pel fet que a l'articulat del text es fan algunes mencions directes a la «Costum de València», que aparentment semblen referir-se només a la ciutat, però habitualment no s'analitza el context en què es van escriure, ni s'estudien altres elements que permetrien tenir un millor criteri sobre la qüestió, raó per la qual fa algun temps que ens vam plantejar la conveniència de realitzar un estudi de conjunt del tema, per tal de tractar de donar una resposta raonada a aquest i altres problemes significatius, si és que els podem considerar com a tals. Així les coses, els primers resultats d'aquest estudi són el principal argument de les pàgines següents, on podrem comprovar que hi ha motius suficients per a concloure que l'any 1238 es va promulgar un sol text legislatiu que porta al mateix pròleg el nom de «Costum de la ciutat i regne de València», títol suficient per deixar aclarida la intenció i la voluntat del legislador i, per tant, esborrar qualsevol dubte al respecte; la qual cosa no era obstacle, o contradicció, amb el fet de què alguns dels seus articles, no molts en realitat, feren referència a institucions municipals concretes, mentre que la resta, la immensa majoria, foren d'aplicació tant a la ciutat com al conjunt del regne de València.

\section{Els primers destinataris de la nova «Costum» valenciana}

El 28 de setembre de 1238 es va signar la carta de capitulació de la ciutat de València. En dit document el rei Jaume I va establir que els musulmans disposarien de vint dies per poder abandonar-la pacíficament, sense cap risc per a les seues persones i béns, la qual cosa significava, almenys teòricament, que a partir del dia 17 d'octubre següent la capital del nou regne cristià de València estaria buida $\mathrm{i}$, per tant, es podria començar a repoblarla de manera ordenada amb els cristians que havien acompanyat el rei en la campanya

\footnotetext{
${ }^{3}$ Per raons d'espai, en aquestes pàgines no tractarem d'aquestes diferències de criteri entre els historiadors, sinó que ens limitarem a extraure i analitzar breument les cites que van fer els mateixos legisladors sobre el verdader caràcter de la «Costum» de 1238 , tema que per a ells no era en absolut un problema.
} 
militar de conquesta, a molts dels quals ja se'ls havia promés la donació de cases i terres quan es produïra la victòria. ${ }^{4}$

El repartiment de les cases de la ciutat de València està prou ben documentat, en haver-se conservat el llibre manuscrit confeccionat pels escrivans de la Cancelleria reial en abril de 1239, per tal de fer el recompte de les cases que s'havien assignat fins a aquell moment. ${ }^{5}$ Molts d'ells, probablement, ja comptaven amb els títols de propietat de la casa o cases rebudes, expedits per dits escrivans, amb els mateixos efectes legals que si les hagueren adquirit en una transacció ordinària de caràcter privat.

Fent un càlcul purament estimatiu, és fàcil comprovar que hi ha més de 3.200 noms d'altres tants donataris. Cert és que, en aquells moments, no havien sigut repartides o ocupades totes les cases disponibles, com es desprén de la lectura del llibre; cert és també que, una volta transcorregut el termini legal de prohibició, molts d'aquells primers donataris farien carta de venda de llurs respectives cases a nous pobladors cristians i se'n tornarien als seus països d'origen; i també és veritat que el fet que només figuren al llibre els noms dels titulars, tots homes, no significa que quan es va començar a redactar el llibre una part d'ells no haguera portat ja les seues famílies per a instal-lar-se definitivament al nou regne, tal com podem interpretar a partir d'algun del articles de la «Costum». Per tant, en 1239 ja devien viure a València uns quants milers de persones, la qual cosa la situava en una posició destacada en el conjunt de ciutats i viles més poblades de la Corona d'Aragó.

\section{Un dret propi per als nous valencians}

A totes aquelles persones i també a totes quantes s'instal'larien més prompte o més tard a la ciutat de València, moltes amb les famílies, els calia disposar d'un dret sobre el qual basar les seues relacions diàries i, a més d'això, per poder anar estructurant no tan sols la ciutat sinó també el nou regne de València, incorporat a la corona de Jaume I a partir de la capitulació de la capital, tot i que a tenor del que sabem hui en dia, el rei tan sols va començar a proclamar-se «rex Valencie» a partir del 17 d'octubre de 1238, si fa no

\footnotetext{
${ }^{4}$ Uns mesos abans, durant el llarg període de setge de la ciutat de València (de juliol de 1237 a setembre de 1238), els escrivans de Jaume I van realitzar una intensa activitat, ja que havien de redactar tota la documentació produïda a conseqüència d'aquell fet militar i, també, tota la que amb caràcter ordinari efectuaven diàriament, perquè el rei també havia de seguir governant la resta de territoris de la Corona d'Aragó. Durant tot aquell temps l'escrivà Guillem, que també va ser l'autor material de la redacció de la carta de capitulació de València, va anotar al volum primer de l'obra coneguda amb el nom de «Llibre del Repartiment de València» (Arxiu de la Corona d'Aragó, Barcelona, Cancelleria, registre 5), unes 890 donacions, individuals o col-lectives, de cases i terres, la immensa majoria de les quals situades a la ciutat de València o al seu voltant més pròxim, a favor de nobles, eclesiàstics i, sobretot, homes de les ciutats i viles d'Aragó i Catalunya, citant en tots els casos els noms dels beneficiaris. A partir de la capitulació de la ciutat (el 28 de setembre de 1238) encara se'n van atorgar al voltant de 444 més, de manera que a la primavera de 1239, quan es farà el recompte de donataris de cases de la ciutat, podem dir que, de forma molt aproximada, s'havien fet almenys al voltant de 1.334 donacions i, si férem la comprovació, una gran part d'elles coincidirien segurament tant en la relació de donataris com en la del recompte; però la comparació entre aquesta xifra i la que ens facilita el volum tercer del «Repartiment» sembla indicar que, més de la meitat de les donacions no es van incloure entre les anotacions oficials conservades de l'escrivà Guillem, sinó que es van atorgar per altres vies que no coneixem en l'actualitat.

${ }^{5}$ Es tracta del volum tercer de l'anomenat «Llibre del Repartiment de València»: Arxiu de la Corona d'Aragó, Barcelona, Cancelleria, registre 7.
} 
fa coincidint amb la finalització del termini de vint dies concedits als musulmans en la carta de dita capitulació, perquè pogueren abandonar-la.

De la mateixa manera que un segle abans, just després de la conquesta de Saragossa en desembre de 1118, el rei Alfons I d'Aragó no va dubtar a concedir de manera tàcita l'imponent fur llatí extens de Jaca com a dret de la nova capital del regne d'Aragó, en el cas de la ciutat i regne de València el rei Jaume I va voler aplicar una metodologia semblant, tot i que a diferència del seu avantpassat no tenia un model de dret valencià preexistent, ${ }^{6}$ raó per la qual va haver de buscar una solució alternativa eficient, ja que el regne de València necessitava un dret ambiciós i complet i, per tant, amb uns referents i una amplitud fins a aquell moment desconeguts a la totalitat del regnes de la península Ibèrica, on fins llavors els únics drets existents tenien un caràcter purament local o comarcal.?

La nova llei del regne de València, per tant, podia constituir un experiment, en no haver condicionants previs al treball dels legisladors, que no van ser altres sinó els juristes de la Cancelleria reial, pels seus coneixements i experiència i, per tant, el rei podia confiar en ells plenament a l'hora de redactar-la. Aquesta iniciativa hauria de pesar en el futur, a l'hora de fer qualsevol modificació, donat el caràcter legal del text, amb la qual cosa tots els canvis haurien de quedar puntualment reflectits, per tal de distingir-los de la redacció inicial. La «Costum de València» de 1238 va servir també per a introduir amb força a la península Ibèrica els principis del «ius commune», ${ }^{8}$ un corrent de pensament de moda a l'època, que els juristes de la Cancelleria ja coneixien, perquè no debades venien usant aquest dret de procedència italiana des de feia més de mig segle, com queda patent a través de la documentació coneguda.

\footnotetext{
${ }^{6}$ La manca d'un dret autòcton va provocar que entre els anys 1233 i 1238 el rei tinguera necessitat d'utilitzar en algun moment el Fur de Saragossa com a dret de referència a l'hora de promulgar cartes de poblament, en alguns dels primers llocs conquerits al regne de València, el cas més significatiu dels quals va ser el de Borriana, en novembre de 1233. El mateix criteri van seguir altres senyors cristians, entre els quals destacava Blasco de Alagón, que va repoblar la vila de Morella i moltes de les aldees del seu terme general, inicialment la vila amb el Fur de Sepúlveda i Extremadura, però ben prompte el va substituir pel de Saragossa. L'orde de l'Hospital, en canvi, va aplicar al castell de Cervera i les poblacions del seu terme general les Costums de Lleida. Una i altra circumstàncies tenien sentit amb caràcter transitori, però no es podia generalitzar ni perpetuar, ja que la propagació de furs forasters podria tindre més endavant conseqüències no desitjades, com de fet n'hi van haver, sobretot quan la noblesa aragonesa va voler reivindicar, després de la promulgació del dret general del regne de València, el manteniment del dret aragonés que havien introduït a través de les cartes de poblament dels llocs dels seus respectius senyorius (Morella, Borriana, Culla, Cervera, l'Alcalatén, etc.).

${ }^{7}$ Els referents més pròxims, en aquells moments per als juristes de la Cancelleria Reial eren el Fur de Saragossa o al seu equivalent de la Costum de Lleida, textos pensats únicament per al seu ús en dites ciutats però no fora d'elles i, en els dos casos, i tot i el seu interés, es tractava de textos d'una extensió relativa, que no cobrien les necessitats que una ciutat com València podia tenir ben aviat, ni menys encara per a les que poguera tenir el conjunt de tot un regne. ${ }^{8}$ Dit corrent de pensament, o «ius commune», procedent de Bolonya, es basava en la recuperació de l'antic dret romà-justinianeu contingut al «Corpus iuris civilis», manat compilar bàsicament entre els anys 528 i 534 per part de l'emperador Justinià, de l'imperi romà d'Orient, que contenia el més selecte de les institucions jurídiques desenvolupades al llarg de més de dotze segles de cultura jurídica romana. Ara bé, com que aquesta obra era molt útil i perfectament recognoscible encara al segle VI, però ja no al segle XII, després de segles d'oblit, els juristes de la Universitat de Bolonya no es van limitar a reconstruir els textos justinianeus, sinó que a més els van explicar exhaustivament a través d'una metodologia extraordinària, la de la glossa, gràcies a la qual es va poder adequar l'antic dret a les necessitats de la nova societat europea que estava esdevenint molt més urbana que en els segles anteriors, i aquell antic dret romà, que durant centúries havia sostingut el major imperi del món, ara també podia ser de gran utilitat per a un nou context social.
} 
La Cancelleria reial estava prou ben organitzada almenys des del temps dels reis Alfons II i Pere II d'Aragó, però a principis del segle XIII, durant la minoria d'edat de Jaume I, es va haver de reforçar més encara durant la regència col-legiada dels nobles i eclesiàstics nomenats l'any 1216 pel papa Innocenci III a dit efecte (Trenchs, 1979). ${ }^{9}$ És molt probable que foren ells mateixos els qui decidiren col-locar al front de la Cancelleria el bisbe de Barcelona, Berenguer de Palou, qui la va regentar fins a la seua mort l'any 1241. El canceller Palou, per tant, va ser qui va donar les instruccions perquè l'any 1238 es confeccionara el text de la nova legislació valenciana, treball segurament dirigit pel jurista format a la Universitat de Bolonya Pere Albert (García Sanz, 1996a), de manera que l'obra es va presentar davant el parlament de notables reunit a la ciutat de València unes poques setmanes després de la conquesta de la ciutat, on va ser aprovat per tots els assistents i just després promulgat pel rei, amb el títol, o la denominació que podem llegir al començament del pròleg, escrit en versió original llatina: «Consuetudines in hac regia civitate Valencie, necnon et toto Regno, et universis, villis, castris, alqueries, turribus et locis aliis in hoc regno hedificatis et hedifficandis [...] dignum duximus compilandas $\gg^{10}$. Amb la qual cosa queda fora de dubte la voluntat d'establir des dels inicis un sol dret territorial, independentment dels fets que en aquells moments el regne de València no fóra altra cosa més que un projecte que calia materialitzar de manera plena i la cita expressa de la ciutat en el títol, abans inclús que la menció al regne, fóra una forma de reconeixement al paper i la importància de la capital del regne, acabada de conquerir.

Quasi al final del mateix pròleg els juristes tornen a posar en boca del rei el mateix concepte, a l'hora de prohibir l'ús d'altres lleis al regne de València, cosa que no s'aconseguiria fins a ben entrat el segle XIV. El text diu: «Prohibemus itaque nullas alias consuetudines in civitate vel aliquo loco regni Valentie sibi locum in aliquo vendicare, sed per istas curia et iudices lites debent difinire». ${ }^{11}$

Just després del pròleg comença el text de la «Costum de València», que en la versió primitiva de 1238 constava d'uns 1.475 articles, o furs, distribuïts en 146 capítols d'extensió variable, ordenats principalment seguint l'orde establert a l'índex del Còdex de l'emperador Justinià, confeccionat en el segle vi a l'imperi romà d'Orient i que contenia una recopilació de milers de lleis romanes, a partir de les quals els legisladors reials van anar seleccionant tot allò que podia ser d'utilitat a l'hora de redactar el nou cos legal valencià i, al mateix temps, van incorporar textos legals d'altres procedències, sobre els quals no és ara moment de parlar-ne, i van redactar també entre quatre i cinc centenars d'articles nous (no se n'ha

\footnotetext{
${ }^{9}$ Els set consellers eren: pel regne d'Aragó, el bisbe de Tarassona García Frontín I i els nobles Jimeno Cornel i Pere Aonés; per Catalunya l'arquebisbe de Tarragona Aspàreg de la Barca i els nobles Guillem de Cervera i Guillem de Cardona; i el mestre de l'orde del Temple Guillem de Mont-rodon. El document original es conserva a: Arxiu de la Corona d'Aragó, Butlles, Innocenci III, lligall 3, núm. 25 (Soldevila, 1968: 100-101).

${ }^{10}$ La transcripció procedeix de l'únic manuscrit llatí de l'obra arribat als nostres dies. És de començaments del segle XIV i es conserva a l'Arxiu de la catedral de València (f. 1v). Pel que fa la traducció romanç del text, la versió més antiga conservada és, com hem dit, la del manuscrit de l'Arxiu municipal de València, on podem llegir: «Costumes, en aquesta reyal ciutat de València, e en tot lo regne, e en totes les viles, castells, alqueries, torres, e en tots altres lochs ... fem e ordenam» (f. 1v).

${ }^{11}$ La versió romanç del text, segons el manuscrit de l'Arxiu Municipal de València diu: «Vedam doncs que nengunes altres Costumes en la ciutat ho en alcun loch del terme altre del regne de València en alcuna cosa no hagen loch, mas per aquestes Costumes la cort e·ls jutges degen los plets jutjar e determenar» (f. 2r).
} 
fet encara un recompte exacte), pensats expressament per a singularitzar l'obra (Garcia Edo, 2012: 11-26). Com es pot deduir, per portar endavant tota aquella tasca va ser necessari un llarg procés d'elaboració, que calia fer amb molta cura, donada la seua extensió i complexitat, amb la qual cosa els legisladors van haver de treballar de manera conjunta durant prou de temps, un fet que invalida la teoria que poguera haver sigut obra d'una única persona, com en ocasions s'ha dit sense cap mena de fonament, per molt voluntariosa i experta que fóra. ${ }^{12}$

\section{Reconstrucció de la versió original de la «Costum» de 1238}

La paraula costum, per tant, era sinònim de llei, en un sentit extens, i, tal com es diu en el pròleg, constituiia el nou cos legal de la ciutat i regne de València a partir de 1238, però, com ja hem indicat abans, el text que coneixem és el que va quedar a la mort de Jaume I, després dels nombrosos canvis que va experimentar des de la seua promulgació, raó que ha fet pensar a diversos historiadors que no era possible reconstruir la versió primitiva del text, opinió que no compartim, ja que, en tractar-se d'un text legal en el qual els diferents legisladors que han introduit canvis han anat deixant la seua empremta cada vegada que han intervingut, tan sols cal realitzar un treball pacient $\mathrm{i}$ acurat per tal de poder recórrer el camí a la inversa, cosa que ja hem demostrat possible amb algun exemple semblant — tot i que no tant extens - de la mateixa època. ${ }^{13}$ Com és natural, el resultat no pot ser perfecte, però sí molt satisfactori, de manera que, en el cas que ens ocupa, tot i que ara en aquestes línies no la podem mostrar amb detall, ja podem dir que la imatge de la «Costum de la ciutat i regne de València» de 1238 se'ns presenta perfectament nítida i segurament molt semblant a com era en el seu estat original.

Fent un resum del procés reconstructor, podem dir que hem partit de la versió coneguda de 1276, de la qual es coneix tant la versió llatina en un sol manuscrit de principis del segle XIV i la versió romanç en diversos manuscrits dels segles XIV i XV, encara que tan sols cal utilitzar el confeccionat en 1329-1330 en les Corts de València de dits anys, ja que està signat notarialment i, per tant, té valor d'original. La comparació entre dites versions llatina i romanç demostra que coincideixen en la seua pràctica totalitat, però no completament. Amb la suma de dites coincidències i divergències, el nombre d'articles o furs de partida és de $1.558,{ }^{14}$ dels quals uns 50 es van afegir després de l'any 1238, probablement en 1271 ,

\footnotetext{
${ }^{12}$ Ens referim a l'atribució de l'obra al jurista i bisbe d'Osca, Vidal de Canyelles, també format a Bolonya i bon coneixedor dels principis del «ius commune», simplement pel fet d'haver estat present en l'assemblea efectuada a València amb motiu de la promulgació de la «Costum».

${ }^{13} \mathrm{Amb}$ la mateixa metodologia vam poder reconstruir l'estat primitiu de les «Costumes d'Eivissa i Formentera», promulgades el 9 de gener de 1236 per Guillem de Montgrí, arquebisbe de Tarragona, l'infant Pere de Portugal, senyor de Mallorca, i el comte Nunó Sanç, senyor del Rosselló, els tres senyors a parts iguals de dites illes: Arxiu Municipal d'Eivissa, Llibre de la Cadena, f. 9r-12r (Còpia del segle Xv). Vam fer la transcripció i publicació en línia del text, el 3 de febrer de 2008: Arxiu Virtual Jaume I, Universitat Jaume I: http://www.jaumeprimer.uji.es/ cgi-bin/arxiu.php?noriginal=000929 [Consulta: 19-4-2019].

${ }^{14} \mathrm{Ja}$ vam establir aquest nombre de furs en una publicació de fa alguns anys (Colón i Garcia Edo, 2002: 168-281), en la qual també vam podem fixar exactament la font documental de més de la meitat dels furs de la «Costum», però no ha estat sinó fins ara quan hem realitzat (usant aquella numeració) la reconstrucció de la versió primitiva de 1238 de dit text, de la qual caldrà fer properament la corresponent edició, ja que ens permet tindre una visió més pròxima a allò que van redactar els juristes de Jaume I.
} 
i uns 33 més podem considerar-los furs ficticis, ja que no són altra cosa més que fragments de la part dispositiva de diversos privilegis reials atorgats pel rei Jaume I entre els anys 1239 i 1253, normes, per tant, que es van incorporar dins del cos de la «Costum de València» en el lloc que els correspondria per raó de matèria, per tal de fer més fàcil recordar la seua existència i poder usar-les sense haver d'acudir a consultar els pergamins originals que les contenien; amb la qual cosa i amb el pas del temps, sense altre argument més que aquell, es van acabar considerant com a vertaders furs, sense ser-ho, fins al final de l'època foral.

Si restem aquestes dos quantitats del total, i sense perjudici del fet que encara es puga afinar un poc més (especialment pel que fa el nombre d'articles o furs ficticis, que podria incrementar-se lleugerament), es pot afirmar amb poc marge d'error que l'any 1238 la «Costum de València» promulgada pel rei Jaume I constava d'uns 1.475 articles o furs. ¿Podríem dir, per tant, que eixe resultat es correspon amb la versió primitiva de la «Costum de València», tal com es va promulgar l'any 1238? La resposta és afirmativa pel que fa a un 83\% del conjunt, que són aproximadament 1.225 articles, dels quals no hi ha cap indicació d'haver-se modificat mai; cosa que sí que es posa de manifest en uns 255 articles, que representarien el $17 \%$ restant del total de l'obra.

En molts dels articles modificats se'ns informa dels canvis de manera genèrica, la qual cosa sembla indicar que no han sigut unes modificacions molt importants. En altres, en canvi, es diu de manera expressa què és el què s'ha canviat, potser per la importància de l'acció o el major zel dels juristes que a cada moment van intervindre en la modificació de la llei, ja que els canvis es van realitzar en un espai de temps prou llarg. Amb aquesta metodologia es podia distingir clarament si en una mateixa llei hi havia hagut una primera o ulteriors redaccions, amb els efectes que això tenia des d'un punt de vista estrictament jurídic.

\section{Una llei tant per a la ciutat com per al regne de València}

La reconstrucció del text primitiu de 1238 deixa més clar l'esperit i la voluntat dels primers legisladors de fer servir una mateixa obra per a atendre les necessitats de la ciutat i regne de València, raó per la qual en algunes ocasions es parla de «costum de València» en referir-se a alguna institució concreta de la ciutat, sobretot quan fan al-lusió a algunes de les competències del justícia, que era la màxima autoritat municipal; però en altres ocasions - i això molts historiadors no ho veuen - els legisladors indiquen que determinats furs son d'aplicació al conjunt del regne. I, per damunt d'aquestes dues circumstàncies, convé recordar que la immensa majoria de l'articulat està redactat de manera que no cita ni la ciutat ni el regne i, per tant, s'entén que tenen un valor tant local com territorial.

Si fem recompte de les vegades que la paraula «costum», o en plural «costumes», ${ }^{15}$ figura en el text primitiu reconstruït de la «Costum de València», apareix en 38 ocasions, de les quals set es troben en el pròleg i tenen un valor neutre, mentre que les restants 31 no es corresponen amb tants altres furs, ja que a voltes en un mateix fur es repeteix la paraula

\footnotetext{
${ }^{15}$ És de notar el caràcter femení de la paraula «costum», precedida en tots els casos on cal indicar-ho, tant en singular com en plural, pels articles «la» $\mathrm{i}$ «les». Tan sols en una ocasió al llarg de tot el text, trobem l'ús de l'article neutre «lo» (fur 687).
} 
dos o més vegades. Sense fer una anàlisi exhaustiva, podríem dir que la paraula «costum» referida amb caràcter exclusiu a la ciutat de València tan sols la trobem en sis furs (17, 32, $34,304,636,780$ ), bàsicament relacionats amb l'ofici i les competències del justícia de la ciutat de València; mentre que amb un doble sentit (ciutat i regne), a voltes indicat de manera directa i a voltes derivat de la lectura completa del fur, la trobem en 11 casos (furs $74,142,687,698,874,949,954,1058,1183,1194,1251)$. Hi podem afegir un tercer grup on la paraula «costum» té un valor neutre, o fa referència a les «bones costumes» $\mathrm{o}$ a les «costumes» de caràcter legal existents en altres territoris (furs 107, 190, 304, 494, 1351).

En canvi, crida l'atenció que la paraula «ciutat» apareix registrada en nombroses ocasions al llarg de l'articulat de la «Costum», ${ }^{16}$ ja que la importància de la ciutat de València era molt gran en $1238 \mathrm{i}$ els legisladors es van preocupar per regular algunes de les institucions municipals més notables, per tal que, des del mateix moment en què es produïra la victòria cristiana i el rei Jaume I entrara triomfalment en la ciutat, aquesta poguera començar a estructurar-se d'una manera eficient i pacífica, i convertir-se en el referent dels nous habitants del regne ${ }^{17}$. Però això no era un impediment, ja que els juristes de la Cancelleria reial van pensar en una fórmula dual, com ja hem dit, segons veurem ara, a propòsit del mateix article 1 de l'obra, on es descriuen els límits del regne de València, i de l'article 2, dedicat als de la ciutat de València. Potser algú pot pensar que el primer article podria haver-se confeccionat «a posteriori», en un replantejament general de l'obra, a partir d'una hipotètica «Costum» municipal prèvia, la qual cosa no sembla possible si comparem la versió llatina de la descripció dels límits del regne, que és molt breu, amb la versió romanç, que duplica el text i fa una millor descripció, ja que es va redactar de nou quan es va efectuar la traducció de tot el text i es tenia un millor coneixement dels límits del territori valencià, uns quinze anys després de finalitzar la conquesta del regne, la qual cosa significa que en 1261 es va modificar sobre un text preexistent, del qual també disposem gràcies a la versió llatina.

Si els dos furs anteriors es referien, per separat, a la ciutat i el regne, el fur 7 prohibeix als cavallers que puguen fer vedats tant a la ciutat com a la resta del territori del regne de València, si no compten amb la prèvia autorització de la corona. En canvi, el fur 10 tan sols fa referència a la ciutat, en prohibir fer llauró en la rambla o l'areny que es troben prop del palau reial de València i del riu Guadalaviar, però sense dir en aquest article que això és «costum» pròpia de la ciutat, cosa per altra banda innecessària. El fur 11 cita el conjunt del regne sense anomenar-lo, en indicar de manera genèrica que no es pot impedir el pas dels camins antics que porten a les heretats, horts, vinyes, alqueries i altres llocs, ni tampoc no es pot reduir l'amplada ni permetre que es deterioren, ja que tenen caràcter i ús públic.

A banda d'aquests exemples tan evidents i variats, si també tenim un cert interés per descobrir què és el què està dient el legislador quan utilitza expressions en diferents articles de l'obra tals com «segons que en la Costum de València és contengut», «segons la Costum de València», «contra la Costum de València sia feita», i altres de característiques

\footnotetext{
${ }^{16}$ L'hem trobada un total de 199 vegades, tot i que en molts furs es conté la paraula «ciutat» dos o més vegades, de manera que el nombre real de furs on figura és prou més reduït.

${ }^{17}$ La paraula «regne» es troba copiada un total de 110 vegades, en un nombre considerable d'articles, circumstància que fins ara no havia interessat analitzar als historiadors preocupats per desvetlar el verdader localisme o territorialitat de l'obra.
} 
semblants, podem afirmar que no s'està referint a una llei exclusiva de la ciutat, sinó que el que s'indica és que en determinades circumstàncies s'ha d'actuar com determina el principi regulador d'una matèria concreta, contingut en un altre article anterior de la mateixa «Costum», la qual cosa mostra, a més a més, la coherència en la confecció del cos legal.

Podem comprovar-ho fent un seguiment d'algunes d'aquestes cites, com la que es troba en el fur 32, relatiu a la manera de fer inquisicions contra els inculpats de qualsevol crim, on es diu que la cort del justícia ha d'actuar «segons que en la Costum de València és contengut» i, tot seguit, fa la corresponent descripció de manera molt detallada, la qual cosa significa que en algun article anterior hauria de figurar contemplada aquella institució. Feta la corresponent cerca comprovem que, en efecte, la competència del justícia està clarament explicitada en el fur 23 , indicant els casos en què s'ha d'efectuar i la metodologia que s'ha de seguir.

El fur 34 assenyala que les inquisicions són competència exclusiva del justícia i que s'han de fer d'acord amb «la Costum de València». Dita regulació es troba tant en el fur 23 com en els immediatament posteriors, però estan redactats de forma que no es fa menció directa a la ciutat de València, de manera que podien ser aplicats a qualsevol altra ciutat o vila del regne de característiques semblants, com podien ser totes aquelles que havien de formar part del patrimoni reial i, a poc a poc, anirien constituint el braç reial del regne de València.

Un nou exemple, amb característiques diferents a l'anterior, el trobem en el fur 142, que estableix la pena d'infàmia per a tots aquells que imposen usures vedades «per Costum de València». La regulació de les usures de jueus i sarraïns es conté en el capítol o rúbrica 68, amb el títol «De usures» (furs 513-514), i disposa especialment que «depuys que la usura serà egual·lada a la sort o al cabal, d'aquí enant la usura no cresca per alcuna estada de temps en neguna guisa», tot amb la intenció d'evitar que per motiu de demora el deute s’incrementara contínuament, de manera que en fóra impossible la cancel·lació. Com és natural, el text d'aquesta rúbrica no fa cap menció explícita a la ciutat, ja que la necessitat de demanar diners a préstec la podia tindre qualsevol persona de qualsevol lloc i la «Costum» la legislava, en conseqüència, pensant en el conjunt del territori.

En el fur 494 s'assenyala genèricament l'obligació que només puguen ser testimonis en qualsevol demanda les persones que no n'hagen estat excloses, segons determinava l'articulat de les «Costumes». En efecte, respecte de la idoneïtat dels testimonis ens hem d'adreçar a un fur previ, el 32, paràgraf segon, que determina que «la cort apel e deman testimonis, los quals testimonis sien de bona fama, e no enemichs, e juren que diran veritat, veén e hoén aquell qui serà encolpat».

D’altra banda, l'article 636 indica que, segons «les Costumes escrites de la ciutat de València», s'haurien de jutjar els plets contra aquelles persones que tenien coses a cens de cavallers, clergues o religiosos, tant si hi havia reclamació d'una part o d'una altra, la qual cosa podria fer-nos pensar en un caràcter purament localista de la norma; però això no es pot sustentar, en canvi, en molts altres casos, per exemple en el fur 635, que indica els tipus de monedes que els contractants podien usar com a referent, a les cartes censals que es feren tant «en la ciutat e en tot lo regne de València».

Així mateix, l'article 687 tracta els drets d'aixovar i esponsalici de les dones aragoneses que contreien matrimoni en el regne de València amb homes de qualsevol població d'aquest 
territori, en el qual cas totes elles tindrien aquells drets «segons lo Costum de València», a no ser que en les cartes nupcials respectives hi haguera pactes en contrari. Per tant, la territorialitat es demostra ací una vegada més i, de fet, pel que fa a aquelles institucions matrimonials concretes, en l'articulat de la «Costum» hi havia una normativa bastant extensa, donada la importància que tenia a l'època en la vida quotidiana de les persones. ${ }^{18}$

D'altra banda, en una ocasió la paraula «costum» s'utilitza com a sinònim de «fur», en singular (fur 1251). És un text que parla de la conservació i els enderrocaments de cases i edificis de la ciutat de València, així com dels danys que es puguen causar a tercers, que s'han de reparar d'acord amb «la costum del barreig», que es pot trobar un poc abans (en el fur 1241), on es regula eixa institució. Per tant, com diem, la paraula «costum» s'empra en aquest cas com a sinònim de «fur», en el sentit d'una norma concreta.

En aquest sentit, la mateixa paraula «fur», entesa singularment com un article qualsevol de la «Costum», es troba també en diverses ocasions, com és el cas de l'article que regula les penes contra aquells que causaran ferides al batlle o al justícia (fur 1225), que seran «la dobla de les penes posades en lo fur de injúries». Sembla que aquest es deu correspondre amb el fur 1175, però al mateix temps aquest darrer es pot posar en relació amb el fur 1182, tots dos inclosos dins del capítol 118, abans citat, titulat genèricament «De injúries».

Tot i que encara se'n poden trobar uns quants exemples més, que abunden en tots els aspectes que de manera tan sumària, però clara, hem presentat ací, acabarem aquesta selecció amb un text (fur 287) que sembla no haver mai experimentat modificacions des de la redacció original de 1238, a través del qual Jaume I va disposar que si es produïen demandes contra qualsevol habitant de la ciutat i regne de València, els demandats tan sols tindrien obligació de respondre-les, amb caràcter ordinari, davant les corts del justícia de la ciutat de València o les dels respectius llocs de residència, i no davant «neguna cort de nostra terra ne d'altra nostra senyoria, conquesta o a conquerre», amb la qual cosa, i de la lectura de les darreres paraules, sembla donar-se a entendre que aquell criteri es va redactar quan encara hi havia terres del regne per conquerir. Per tant, sembla que no hi ha dubte que es degué promulgar en 1238, quan castells tan propers com el de Morvedre, i altres de més al nord com el d'Onda i tota la serra d'Eslida, encara restaven en mans de musulmans, així com també ho estava tota la meitat sud del regne que es preveia conquerir.

\section{5. «Una consuetudo in toto regno et civitate Valencie sit perpetuum»}

Si no foren prou tots els exemples anteriors, completarem el nostre argumentari dedicant un espai singular a la prova definitiva. A més de les dues vegades que, com hem vist, el títol de «Costum de la ciutat i regne de València» figura en el pròleg, i per obviar possibles escrúpols derivats de l'esperit literari d'eixe text d'encapçalament, probablement ningú ja no podrà tenir-ne cap si el títol complet el tornem a trobar formant part d'un fur, per tant d'una llei, i també per partida doble; i, com que aquest fur tampoc presenta cap indici d'haver estat modificat, això vol dir que es va redactar per primera vegada en 1238 i va ser confirmat tal qual en 1261.

\footnotetext{
${ }^{18}$ Sobre l'organització econòmica del matrimoni valencià a l'època foral, en general, i sobre institucions jurídiques concretes vinculades a aquesta matèria, vegeu Garcia Sanz (1996b: 125-150).
} 
Ens estem referint al fur 74, que declara la «Costum» com l'única llei de la ciutat i regne de València, de la mateixa manera que posa de manifest la voluntat de què en tot el territori hi haja una sola moneda pròpia i uns pesos i unes mesures oficials i públiques, per garantir la unitat de criteri en tots els actes que se'n puguen derivar del seu ús. El fur es troba a la rúbrica 10 de la «Costum», titulada «De constitutionibus et mandatis principum», ${ }^{19}$ que consta de tres articles dedicats a remarcar la importància del dret documental, però no en general sinó tan sols aquell que emana de la voluntat del príncep, que no és sinó una manera de fer al·lusió a la voluntat del rei. És aquest qui dicta «constitutionibus et mandatis» (fur 72), que són una mostra palpable de l'excel·lència del seu govern i del seu poder, una característica que els juristes del «ius commune» van procurar difondre i d'això se'n va derivar una part de l'èxit que va tenir aquest corrent de pensament. La paraula «constitució», a més, cal entendre-la no en el sentit més ordinari i actual del mot, sinó com a manament del príncep, originàriament l'emperador de Roma i, en el segle XIII a València, el rei Jaume I, a qui es considera la representació màxima del poder i per la seua autoritat l'única de qui pot emanar una llei de les característiques que ens ocupa. Per això, la seua paraula es manifesta a través de les seues «letres», sense les quals ningú està acreditat per representar-lo (fur 73).

El dret documental té a partir del segle XIII una enorme influència en la societat de l'època, com mai no l'havia tingut des de la caiguda de l'imperi romà d'Occident, i això va ser per influència de l'expansió del notariat italià del «ius commune», que tenia com a finalitat dotar els professionals de la notaria d'instruments legals que pogueren donar solució a tota mena d'actes de la vida quotidiana, a través de la triple divisió de la matèria pròpia del notariat en contractes, successions i documentació judicial.

En aquest sentit, la «Costum de València» de 1238 és una manifestació excel·lent de dret documental i mostrava al llarg de la redacció el poder del rei com a legislador potent, del qual es pot esperar tot, i sense el qual no hi ha esperança. D'acord amb eixa autoritat, el fur 74 en la seua forma original llatina establia que: «Una consuetudo, una moneta lege, pondere et figura, una alna, unum carterium, unus almutus, una fanecha, unum caphitium, una uncia, una marcha, una libra, una arova, unus quintallus et unum pondus et una mensura, in toto regno et civitate Valencie sit perpetuum $»^{20}$. En aquesta ocasió, doncs, el legislador situava en primer lloc la menció al regne i posteriorment feia la de la ciutat, en consonància amb el mateix tenor de la norma.

En relació amb tot això, cal indicar que, com s'ha dit, la primera de les dos grans modificacions de la «Costum» es va produir entre els anys 1260 i 1261, quan es van portar endavant els treballs de millora d'un nombre significatiu d'articles o furs, tal com consta anotat en cada un d'ells, i la traducció de tot el text, ja que en aquells temps s'estava començant a adoptar una política d'apropament d'alguns textos legals als destinataris dels

\footnotetext{
${ }^{19}$ En versió romanç es deia: «Dels establiments e dels manaments del príncep». Podem comprovar que s'ha traduït la paraula «constitutionibus» per «establiments», la qual cosa difumina un poc als nostres ulls el sentit originari de la paraula, tot i que els traductors de 1261, que eren juristes, sabien perfectament què és el que estaven interpretant. ${ }^{20}$ En llatí, segons el manuscrit de l'Arxiu de la Catedral de València (f. 5v). En romanç, segons el manuscrit de l'Arxiu Municipal de València, es diu: «Una Costum, una moneda de lig e de pes e de figura, una alna, un quarter, un almut, una fanecha, una onça, un march, una liura, una arrova, un quintar, e un pes e una mesura, en tot lo Regne e en la Ciutat de València sia per tots temps» (f. $7 \mathrm{v}$ ).
} 
mateixos i, també, dels usos i les pràctiques legals que se seguien davant dels tribunals de justícia, de manera que la traducció de la «Costum» a la llengua romanç permetia, almenys teòricament, que els membres del Consell municipal de la ciutat de València, principals usuaris de la mateixa, i els de la resta de poblacions que també gaudien d'ella — molts dels quals no eren juristes - pogueren entendre en romanç el text d'unes lleis que alguns podien llegir i, en tot cas, els assessors legals les podien explicar més fàcilment, si era precís.

El següent pas es va donar l'any 1264, quan el rei Jaume I va ordenar que els tribunals de justícia escrigueren en romanç la documentació que produïen, amb la qual cosa s'aconseguia apropar les resolucions judicials als contendents, els quals podien entendre fàcilment la decisió del jutge i saber a què havien d'atenir-se, ja que no sempre se'ls hi expedia còpia de la sentència en paper o en pergamí. El manament del rei es va complir immediatament, com ho demostra l'existència del llibre del justícia d'Alcoi, corresponent a l'any citat i escrit en romanç valencià, i de pocs anys després són també els de Cocentaina i València respectivament. També se'n conserva un significatiu testimoni de l'any 1286, escrit en romanç aragonés, que és el llibre del justícia de la ciutat de Sogorb.

Entre els canvis realitzats pels juristes reials en 1261 figuren diversos aclariments i confirmacions de textos de 1238, entre els quals destaca l'afegit incorporat al text que ens ocupa, deixant absolutament clara la territorialitat de la norma, per si de cas era dubte encara en aquell moment per a alguna persona el contingut d'allò que s'havia ordenat originàriament: «Addidit dominus rex quod ita intelligatur forum in toto regno Valencie sicut in civitate». ${ }^{21}$

\section{Conclusions}

Primera. La denominació oficial del text legislatiu extens atorgat pel rei Jaume I als valencians, unes setmanes després de la capitulació de la ciutat de València, figura per duplicat en el pròleg de l'obra, i també en l'article 74, amb el nom de «Costum de la ciutat i regne de València», tot i que per abreujar solem dir únicament «Costum de València».

Segona. De la forma extensa de la denominació es desprén el caràcter territorial del text des de l'any 1238, afirmació ratificada per la gran quantitat d'articles que fan referència conjunta, o separada, no tan sols a la ciutat sinó també al regne de València, la qual cosa significa que, en un text de l'extensió del que ens ocupa, el legislador a voltes podia remarcar l'existència de certes institucions pròpies de la ciutat. En aquests casos ho feia expressament amb l'ús de la paraula «Costum», i a voltes amb la forma «Costum de València» (també en plural en els dos casos), però l'anàlisi de les manifestacions d'aquesta paraula en els furs on apareix, posant-les en relació amb els altres furs als quals fa referència, indica que els legisladors s'estaven referint bàsicament a certes competències pròpies de l'ofici de justícia de la ciutat de València i no al cos legislatiu en conjunt.

Tercera. Al llarg de l'articulat de la «Costum de València» hi ha també una gran quantitat de mencions a altres paraules, com ara «regne», «ciutat» $\mathrm{O}$ «fur», localitzades per

\footnotetext{
${ }^{21}$ En llatí en el manuscrit de l'Arxiu de la Catedral de València (f. 5v). En romanç, en el manuscrit de l'Arxiu Municipal de València diu: «Enadex lo senyor rey que axí sia entès lo fur en tot lo regne de València com en la ciutat» (f. $7 \mathrm{v})$.
} 
separat la major part de les ocasions, que demostren que eren utilitzades normalment pels legisladors a l'hora de compondre el cos legal valencià, per explicar qüestions semblants a les que es volien referir quan usaven la paraula costum.

Quarta. El caràcter territorial del cos legal és confirmat de manera definitiva pel contingut del fur 74, que tenia valor de llei i que afirma, ja en la redacció de 1238, que només hi podia haver una «Costum» per a la ciutat i el regne de València.

Cinquena. La «Costum» de 1238 ha arribat als nostres dies amb indicació de totes o la major part de les modificacions i afegits efectuats amb posterioritat a la seua promulgació, de manera que tornant el camí enrere es pot reconstruir amb bastant fidelitat l'aspecte que tenia originalment, la qual cosa haurà de donar lloc en un futur pròxim a la seua publicació, que permetrà formar-se una imatge bastant diferent de la que tenim en l'actualitat, quan fem ús de les diverses edicions existents de l'obra.

\section{BIBLIOGRAFIA}

Colón, G. i A. García (1970-1999): Furs de València, Barcelona, Barcino, vols. I-VIII.

Colón, G. I V. Garcia Edo (2002): Furs de València, Barcelona, Barcino, vol. IX,

CORTÉs, J. (2001): Liber privilegiorum civitatis et regni Valencie. I. Jaume I. (1236-1276), València, Publicacions de la Universitat de València.

Garcia Edo, V. (1996): «La redacción y promulgación de la "Costum" de Valencia», Anuario de Estudios Medievales, 26-2, 713-728.

Garcia Edo, V. (2008): La obra legislativa de Jaime I de Aragón. 1208-1276, Castelló de la Plana, Universitat Jaume I.

Garcia Edo, V. (2012): «La gestació dels Furs de València», Comentaris a les lleis civils valencianes, Barcelona, Institut d'Estudis Catalans.

Garcia Sanz, A. (1996a): «El jurista Pere Albert i la seva obra», Estudis històrics $i$ documents dels arxius de protocols, 14, 7-38.

Garcia SAnZ, A. (1996b): Institucions de dret civil valencià, Castelló de la Plana, Universitat Jaume I.

Soldevila, F. (1968): Els primers temps de Jaume I, Barcelona, Institut d'Estudis Catalans.

Trenchs Odena, J. (1979): «La Cancillería de Jaime I: cancilleres y escribanos», Paleographica, diplomàtica et archivistica. Studi in onore di Giulio Battelli, Roma, Scuola Speciale per Archivisti e Bibliotecari dell’Università di Roma, 95-128.

\section{BIONOTA}

\section{Vicent Garcia Edo}

És doctor en Història per la Universitat de València (1990) i doctor en Dret per la Universitat Jaume I de Castelló, així com Professor Titular d'Història del Dret en aquesta darrera universitat. Durant més de trenta anys s'ha dedicat a l'estudi i edició de textos històrico-jurídics dels territoris de la Corona d'Aragó, especialment d'època medieval i en relació amb els Furs de València i els Furs d'Aragó. És impulsor de l'Arxiu Virtual Jaume I i autor d'una trentena de llibres i més de seixanta capítols de llibre i articles relacionats amb la història medieval i la història del dret. Actualment treballa en una nova edició cronològica dels Furs de València. 